\title{
Opiate and Cerebral Atrophy
}

\author{
Kapil Zirpe ${ }^{1}$, Shrirang N Bamne ${ }^{2}$ \\ Indian Journal of Critical Care Medicine (2020): 10.5005/jp-journals-10071-23402
}

Heroin, morphine, and other opiates trace their origins to a single plant, the opium poppy. ${ }^{1}$ The opium poppy (Papaver somniferum) from which opium is derived is one of the earliest plants, which was recorded to have medicinal use. ${ }^{2}$ Cultivation of the plant dates back to the earliest years of human civilization, and opium use was well-known in ancient Mesopotamia. ${ }^{3}$ The narcotic drug has been used both recreationally and as a medicine for centuries. Opium clay tablets are the earliest prescriptions found in Sumerian civilization, 8000 years ago. ${ }^{3,4}$ Ancient Greeks, Indians, Chinese, Egyptians, Romans, Arabs, and Europeans from renaissance to now knew opium as an ever-approved next-door medicine-a panacea for all ailments. ${ }^{3}$ Opium use by known leaders and personalities like Homer, Franklin, Napoleon, Coleridge, Poe, Shelly, Quincy, Hitler, and many more have removed the label of immorality from its use. ${ }^{3}$ Opium derivatives, including morphine, became widely used as pain relievers, particularly in the 1800 s. $^{5}$

Are the opioids a curse or cure? Opiates are both a dangerous recreational drug and the nature's best form of pain relief. Opioids having dependency and abuse potentials, multiple cellular and molecular mechanism involved in it, one important of which is feedback inhibition of endogenous opioid synthesis.

Opium like recreational drug abuse is a serious health problem which poses detrimental effects on the central nervous system. Neuroimaging plays a pivotal role in detection of these abnormal changes in the brain associated with the drug abuse. ${ }^{6}$ Study focuses on the grading of cerebral atrophy in the opioid-addicted patients and their association with the age and duration of opioid abuse.

Commonly abused opium and its derivatives are afeem, a latex extract of poppy plant, and bhukki, a preparation of dried leaves of poppy plant, are consumed orally. Other abused synthetic opioid chitta, the famous local name for heroin, is either inhaled or taken intravenously for its recreational effect. It is one of the costlier preparations of opioid next to buprenorphine. Buprenorphine is a synthetic opioid taken orally and also a costlier abused synthetic drug compared to tramadol. ${ }^{7,8}$

Chronic opioid use causes not only drug dependency but impaired brain functioning from brain atrophy. ${ }^{9-11}$

A retrospective study in Punjab was carried out on 40 patients of opioid abuse who were admitted to the intensive care unit of the hospital over a period of 2 years. Magnetic resonance imaging scan of these patients was done using Siemens Avanto 1.5 Tesla scanner. All the patients were male, with 25 patients having varying degrees of cerebral atrophy as assessed by Pasquier Scale. Majority of the patients $(n=14)$ on chronic opioid abuse had a global cortical atrophy score of 1 indicative of mild cerebral atrophy. The associated factors like duration of abuse and the age of presentation had significant association with the cerebral atrophic changes in the brain $(p<0.05)$. Opioid-dependent patients with long-term substance abuse had probable association with the atrophic changes in brain as assessed from neuroimaging.
${ }^{1}$ Neuro Trauma Unit, Grant Medical Foundation, Ruby Hall Clinic, Pune, Maharashtra, India

${ }^{2}$ Neuro Trauma Unit, Ruby Hall Clinic, Pune, Maharashtra, India

Corresponding Author: Kapil Zirpe, Neuro Trauma Unit, Grant Medical Foundation, Ruby Hall Clinic, Pune, Maharashtra, India, Phone: +91 9822844212, e-mail: kapilzirpe@gmail.com

How to cite this article: Zirpe K, Bamne SN. Opiate and Cerebral Atrophy. Indian J Crit Care Med 2020;24(4):218-219.

Source of support: Nil

Conflict of interest: None

The progressing age and longer duration of drug abuse may foster significant alterations in the brain structure, leading to varied degree of cerebral atrophy. ${ }^{12}$

Maximal opioid abused duration was seen up to 12 years, beyond which there was a decrease in opioid continuation, and probably this decrease in incidences from abuse-related issues, increasing age and dangling economic conditions. Abuse was relatively more in rural population and among those with less education. As obvious, middle-aged population commonly involved in opioid abuse. Significant proportion (62.5\%) of chronic opioid abusers had variable degree of cerebral atrophy. Ten percent of abusers developed severe grade atrophy with severe ventricular enlargement.

People need to be educated not only about the stringent legal conditions for opioid use but also about opioid addiction and its adverse effect on health, career, and the overall life.

\section{References}

1. Schiff PL. Opium and its alkaloids. Am J Pharm Educ 2002;66(2):188196.

2. Heydari M, Hashem Hashempur M, Zargaran A. Medicinal aspects of opium as described in avicenna's canon of medicine. Acta medicohistorica Adriatica 2013;11(1):101-112.

3. Bandyopadhyay S. An 8,000-year history of use and abuse of opium and opioids: how that matters for a successful control of the epidemic? Neurology 2019;92(Suppl. 15):(P4. 9-055).

4. Krikorian AD. Were the opium poppy and opium known in the ancient near east? J Hist Biol 1975(1):95-114.

5. Schmitz R. Friedrich wilhelm sertürner and the discovery of morphine. Pharm Hist 1985;27(2):61-74.

6. Tamrazi B, Almast J. Your brain on drugs: imaging of drug-related changes in the central nervous system. Radiographics 2012;32(3): 701-719. DOI: 10.1148/rg.323115115.

7. Molfenter T, Fitzgerald M, Jacobson N, McCarty D, Quanbeck A, Zehner M. Barriers to buprenorphine expansion in Ohio: a timeelapsed qualitative study. J Psychoactive Drugs 2019;51(3):272-279. DOI: 10.1080/02791072.2019.1566583.

(0) The Author(s). 2020 Open Access This article is distributed under the terms of the Creative Commons Attribution 4.0 International License (https://creativecommons. org/licenses/by-nc/4.0/), which permits unrestricted use, distribution, and non-commercial reproduction in any medium, provided you give appropriate credit to the original author(s) and the source, provide a link to the Creative Commons license, and indicate if changes were made. The Creative Commons Public Domain Dedication waiver (http://creativecommons.org/publicdomain/zero/1.0/) applies to the data made available in this article, unless otherwise stated. 
8. Art Van Zee MD, Fiellin DA. Proliferation of cash-only buprenorphine treatment clinics: A threat to the nation's response to the opioid crisis. Am J Public Health 2019;109(3):393-394. DOI: 10.2105/ AJPH.2018.304899.

9. Christova P, James LM, Engdahl BE, Lewis SM, Carpenter AF, Georgopoulos AP. Subcortical brain atrophy in gulf war illness. Exp Brain Res 2017;235(9):2777-2786. DOI: 10.1007/s00221-017-5010-8.

10. Wright MJ, McArthur DL, Alger JR, Van Horn J, Irimia A, Filippou M, et al. Early metabolic crisis-related brain atrophy and cognition in traumatic brain injury. Brain Imaging Behav 2013;7(3):307-315. DOI: 10.1007/s11682-013-9231-6.

11. González-Reimers E, Romero-Acevedo L, Espelosín-Ortega E, Martín-González MC, Quintero-Platt G, Abreu-González P, et al. Soluble klotho and brain atrophy in alcoholism. Alcohol Alcohol 2018;53(5):503-510. DOI: 10.1093/alcalc/agy037.

12. Singla A, Singh P, Panditrao M, Panditrao MM. Is Chronic Opioid Abuse Associated with Cerebral Atrophy? An Observational Study. Indian J Crit Care Med 2020;24(4):276-280. 